\title{
Evaluation of the Predictive Power of the Health Belief Model on the Care of Kidney in Type 2 Patients With Diabetes: a Cross- sectional Study
}

mallihe faramarzi

Arak University of Medical Sciences

mohsen shamsi ( $\square$ mohsen_shamsi1360@yahoo.com)

Arak University of Medical Sciences https://orcid.org/0000-0003-4033-8041

mahboobeh khorsandi

Arak University of Medical Sciences

amir hashyani almasi

Arak University of Medical Sciences

\section{Research}

Keywords: Kidney failure, Care of kidney, Diabetes Care, Health Education, Health Belief Model

Posted Date: August 3rd, 2021

DOI: https://doi.org/10.21203/rs.3.rs-757538/v1

License: @ (1) This work is licensed under a Creative Commons Attribution 4.0 International License. Read Full License 


\section{Abstract}

Background: Kidney failure is one of the most important late complication in type 2 patients with diabetes, so more of half-people are wait to graft kidney are people that caused to diabetes. The purpose of this study, was predict to care of kidney in type 2 diabetes patients based on Health Belief Model (HBM).

Methods: In this analytical cross-sectional study, 242 patients with type 2 diabetes select with simple sampling of health centers in Arak ( a city in Iran) in 2020 and health behaviors of kidneys collected based on HBM with reliable and validity of questionaries' and analyses by linear regression logistic.

Results: The mean age of patients was $47.51 \pm 7.86$ years. FBS average was $159.65 \pm 55.01 \mathrm{mi} / \mathrm{dc}$ and average of performance of patients about care of kidney was 30/31 $6 / 42$. Among HBM construct predicted about \%38 perceived severity, \%67.6 knowledge, $\% 31.8$ self-efficacy and \%16.4 internal cues to action, these cases have the most power for prediction and total of construct predict health behavior of kidneys that are about $\% 49$.

Conclusion: This study showed that increasing patients information in field of recognizing kidney failure, emphasis on role of cues to action and finally increasing self-efficacy in patients with type 2 diabetes about care of kidney should be emphasis in education programs for preventing of kidney failure.

\section{Background}

Diabetes is prevalent metabolic disease in world that outbreak of it is increasing in developed and developing countries, so based on who report, outbreak of 2 type diabetes was about 8.5 percent in Iran in 2013 year and will achieve about $12.3 \%$ in 2035 years [1] direct cost for this disease allocate about \% 2.5 to $\% 15$ of hygienic budget in different countries [2].

On the other hand absence of suitable control in diabet disease cause important complication such as retinophaty, nephrophaty and neuropathy and in among them diabetic nephropathy have more importance, because significant number are diabetes dialyses patients [3]. Although in past, infections and inflammation disease were the most prevalent factors that cause kidney disease such as glomerulonephritis but now, diabetes is the most prevalent disease that cause kidney complication in feature [3-4]. Study performed in united states and showed diabet and high blood pressure are the most prevalent factors that caused kidney disease and they were responsible more than $50 \%$ causes that damage to kidney [5] and prevalence of kidney disease in diabetes patients reported $35.5 \%$ in Ethiopia [6].

30 to 40 percent of diabet patients affected to nephropathy for next 10 years due late reorganization. [4, 7]. Diabetes patients that perform dialyses have $22 \%$ higher mortality in first year in comparison with diabetic patients [8]. Since survival is low in patients perform dialyses relative to non - dialyses patients, prevention of diabet nephropathy have the most importance for perform hygienic and health behaviors [9].

Reorganization in hygienic behaviors for patients should be perform based on behavioral models. One of effective models for recognizing behavioral factors in diabetic patients is HBM. Because of presence perceived susceptibility construct and perceived barrier in HBM and since hygienic behavior valid of individual beliefs in field of fear of health threat and evaluation of preventing benefit and barriers. Use of hygienic belief model is suitable in field of care behaviors of kidneys and insatiable to prevent kidney complication in diabetic patients. Pay attention to this subject, study don't find for this subject, therefore this study performed and purpose of it determine evaluation of the predictive power of the Health Belief Model on the care of kidney in type 2 patients with diabetes.

\section{Methodology}

\section{Design and setting of the study}

This is analytic cross-sectional study that performed on 242 people of type 2 diabetic patients referring to health centers in Arak city (Iran center) in 2020 year and simple sampling selected of health centers. 
Volume of needed sample account to 242 patients in available formula and we pay to Alfa 5 percent this performance study by Shabibi et al [10].

$n=\frac{Z^{2} \times P \times(1-P)}{d^{2}}$

Inclusion criterion to study for type 2 diabetes patients with having 5 years' education, between 30 to 60 years. Exclusion criterion was involved lack of inclination to take part in study.

In this study predictor variables was construct of HBM (susceptibility severity, benefit, barrier, internal and external cues to action, selfefficacy) and outcome variable was preventing behaviors that caused kidney complication in patients with diabetes.

\section{Data collection tool}

In this study tool for collecting information was questionnaire that provided based on HBM that are consist of 3 parts. 1 part is consisting of demographic characteristics that involve age, level of education, level of income, and so on. 2 part are consist of knowledge questions (9 questions) and 3 part are consist of construct questions about HBM that are consist of perceived susceptibility ( 7 questions), perceived severity (6 questions), perceived barriers (5 questions), perceived benefits (6 questions), selfefficient (7 questions), internal cues to action (6 questions), external cues to action (6 questions) and performance (10 questions) that provided for preventing behaviors that caused kidney complication in type 2 diabetic patients. Score accounted based on 100 number of every questionnaire.

For determining validity, available questionnaire used of content validity method, therefore questionnaire consider based on HBM and consider to pay attention to provided creditable sources and consider by creditable panel expert, after accounting content validity ration (CVR) 76.32 and content validity index (CVI) 88.40 confirmed.

\section{Data analysis}

Collected information of questionnaire achieved after entry to SPPSS software (Ve 16), that confirmed with statistical test, T-test, likelihood Ratio chi square, fisher Exact Test, Analyses linear regression and also confirmed with data normal distribution with Kolmogorov-Smirnov test. All of tests perform in meaning level 0.05 .

\section{Ethical considerations}

This study was conducted in accordance with the declaration of Helsinki. This study was conducted with approval from the Ethics Committee of Arak university of medical sciences (Approval ID: IR.ARAKMU.REC.1399.045). Written informed consent was obtained from all participants, and data are being kept confidential and anonymous.

\section{Results}

The mean and standard deviation age of patients was $47.51 \pm 7.86$ years and Average FBS in patients were $159.65 \pm 55.01$ milligram in deciliter, other demographic characteristics in samples delivered in Table 1. 
Table 1

Distribution of demographic variables in patients with diabetes

\begin{tabular}{|c|c|c|c|}
\hline Variables & & Frequency $(\mathrm{N})$ & Percent (\%) \\
\hline \multirow[t]{2}{*}{ Sex } & Female & 172 & 70.8 \\
\hline & Male & 70 & 29.2 \\
\hline \multirow[t]{2}{*}{ Marital status } & Married & 222 & 91.6 \\
\hline & Single & 19 & 8.4 \\
\hline \multirow[t]{3}{*}{ Range of education (years) } & Less than 5 years & 125 & 51.4 \\
\hline & $5-10$ years & 46 & 19.4 \\
\hline & $11-15$ years & 71 & 29.2 \\
\hline \multirow[t]{3}{*}{ Occupation } & Unemployed & 58 & 24.1 \\
\hline & Housewives & 161 & 66.4 \\
\hline & Employee & 23 & 9.5 \\
\hline \multirow[t]{2}{*}{ History of kidney disease } & Yes & 1 & 0.5 \\
\hline & No & 241 & 99.5 \\
\hline \multirow[t]{2}{*}{ History of referring to the physician for kidney examination } & Yes & 112 & 48.6 \\
\hline & No & 125 & 51.4 \\
\hline \multirow[t]{2}{*}{ Heath Insurance } & Yes & 227 & 93.8 \\
\hline & No & 15 & 6.2 \\
\hline \multirow[t]{3}{*}{ Type of treatment } & Diet & 15 & 6.2 \\
\hline & Tablet & 199 & 84.7 \\
\hline & Insulin injection & 22 & 9.1 \\
\hline \multirow[t]{2}{*}{ Smoking } & Yes & 21 & 9 \\
\hline & No & 221 & 91 \\
\hline
\end{tabular}

Average of knowledge of patients in this study were $69.7 \pm 15.15$ and average of performance about care of kidneys were $75.77 \pm 16.05$. Average of mean and standard deviation of construct HBM showed in in Table 2. 
Table 2

Mean and standard deviation of health belief model construct about kidney care in patients with diabetes

\begin{tabular}{|lllll|}
\hline Variable & Mean & standard deviation & minimum score & maximum score \\
\hline Knowledge & 69.7 & 15.5 & 11.12 & 100 \\
\hline Perceived susceptibility & 82 & 12.6 & 14.29 & 100 \\
\hline Perceived severity & 89 & 12.5 & 16.67 & 100 \\
\hline Perceived barriers & 50.6 & 17.7 & 20 & 100 \\
\hline Perceived benefits & 92.3 & 12.6 & 16.6 & 100 \\
\hline Perceived self-efficacy & 76.9 & 16.5 & 14.29 & 100 \\
\hline Internal cues to action & 78.1 & 18.4 & 16.67 & 100 \\
\hline External cues to action & 59.9 & 16.1 & 16 & 100 \\
\hline Care of kidney & 75.77 & 16.05 & 10 & 100 \\
\hline
\end{tabular}

In this study, there are positive and meaning relationship between performance and self-efficiency $(P=0.00, r=\% 413)$ also there are direct and meaning relationship between perceived severity, perceived benefits, internal and external cues to action with performance in field of preventing kidney complication in diabetic patients $(P<0.05)$ and also there were meaning relationship between performance and perceived barriers $(P=0.00, r=0.302)$ infield of preventing kidney complication in diabetic disease (Table 3$)$. 
Table 3

Correlation of health belief model construct with the performance of patients with diabetes about kidney care

\begin{tabular}{|c|c|c|c|c|c|c|c|c|c|}
\hline Variable & Knowledge & $\begin{array}{l}\text { Perceived } \\
\text { susceptibility }\end{array}$ & $\begin{array}{l}\text { Perceived } \\
\text { severity }\end{array}$ & $\begin{array}{l}\text { Perceived } \\
\text { barriers }\end{array}$ & $\begin{array}{l}\text { Perceived } \\
\text { benefits }\end{array}$ & $\begin{array}{l}\text { Perceived } \\
\text { self- } \\
\text { efficacy }\end{array}$ & $\begin{array}{l}\text { Internal } \\
\text { cues to } \\
\text { action }\end{array}$ & $\begin{array}{l}\text { External } \\
\text { cues to } \\
\text { action }\end{array}$ & $\begin{array}{l}\text { Care } \\
\text { of } \\
\text { kidney }\end{array}$ \\
\hline \multicolumn{10}{|l|}{ Knowledge } \\
\hline $\begin{array}{l}\text { Perceived } \\
\text { susceptibility }\end{array}$ & $r=0.19 \star *$ & & & & & & & & \\
\hline \multirow{2}{*}{$\begin{array}{l}\text { Perceived } \\
\text { severity }\end{array}$} & $r=0.026$ & \multirow[t]{2}{*}{$r=0.178^{\star \star}$} & & & & & & & \\
\hline & $p=0.698$ & & & & & & & & \\
\hline \multirow{2}{*}{$\begin{array}{l}\text { Perceived } \\
\text { barriers }\end{array}$} & $r=-0.157$ & \multirow[t]{2}{*}{$r=-0.375^{\star \star}$} & \multirow[t]{2}{*}{$\mathrm{r}=-0.228^{\star *}$} & & & & & & \\
\hline & $p=0.16$ & & & & & & & & \\
\hline \multirow{2}{*}{$\begin{array}{l}\text { Perceived } \\
\text { benefits }\end{array}$} & $r=0.002$ & \multirow[t]{2}{*}{$r=0.218^{\star *}$} & \multirow{2}{*}{$\begin{array}{l}r= \\
0.471^{\star *}\end{array}$} & \multirow{2}{*}{$\begin{array}{l}r \\
=-0.212^{\star \star}\end{array}$} & & & & & \\
\hline & $p=0.980$ & & & & & & & & \\
\hline \multirow{2}{*}{$\begin{array}{l}\text { Perceived } \\
\text { self-efficacy }\end{array}$} & $r=0.126$ & \multirow[t]{2}{*}{$r=0.195^{\star *}$} & $r=0.073$ & \multirow[t]{2}{*}{$r=-0.384^{\star *}$} & \multirow{2}{*}{$\begin{array}{l}r= \\
0.262 * \star\end{array}$} & & & & \\
\hline & $p=0.056$ & & $p=0.276$ & & & & & & \\
\hline \multirow{2}{*}{$\begin{array}{l}\text { Internal cues } \\
\text { to action }\end{array}$} & $r=0.095$ & $r=0.057$ & $r=0.058$ & \multirow{2}{*}{$\begin{array}{l}r= \\
-0.203 * \star\end{array}$} & \multirow{2}{*}{$\begin{array}{l}r= \\
0.218^{\star \star}\end{array}$} & \multirow{2}{*}{$\begin{array}{l}r= \\
0.510 * *\end{array}$} & & & \\
\hline & $p=9.148$ & $p=0.395$ & $p=0.388$ & & & & & & \\
\hline \multirow{2}{*}{$\begin{array}{l}\text { External } \\
\text { cues to } \\
\text { action }\end{array}$} & $r=0.083$ & $r=0.076$ & $r=-0.031$ & $R=-0.121$ & $r=0.00$ & $r=0.345^{\star}$ & \multirow{2}{*}{$\begin{array}{l}r= \\
0.480 * *\end{array}$} & & \\
\hline & $p=0.209$ & $p=0.255$ & $p=0.647$ & $p=0.068$ & $p=0.997$ & $\star *$ & & & \\
\hline \multirow{3}{*}{$\begin{array}{l}\text { Care of } \\
\text { kidney }\end{array}$} & $r=0.114$ & $r=0.110$ & \multirow{3}{*}{$\begin{array}{l}\mathrm{R}= \\
0.228 * *\end{array}$} & \multirow{2}{*}{$\begin{array}{l}r= \\
-0.302 * *\end{array}$} & \multirow[t]{2}{*}{$r=0.164^{*}$} & $r=0.413^{*}$ & \multirow{2}{*}{$\begin{array}{l}r= \\
0.371 * *\end{array}$} & \multirow{2}{*}{$\begin{array}{l}r= \\
0.201 *\end{array}$} & \\
\hline & $p=0.089$ & $p=0.106$ & & & & $\star *$ & & & \\
\hline & & & & & & & & $\star \star$ & \\
\hline \multicolumn{10}{|l|}{$*_{p}<0.05$} \\
\hline$\star \star p<0.01$ & & & & & & & & & \\
\hline
\end{tabular}

Also patients reported that they haven't awareness infield influence diabet on kidneys (\%35), high costs for meeting doctors (\%28), don't having enough time for refer to doctor (\%14) are the most important perceived barrier by patients. Funding show that the greatest external cues to action in field of preventing of kidney complication in diabetes are consist of 81 doctors (33.3\%), 69 nurses and workers in health centers (28.4\%). Also the greatest internal cues to action are consist of having health sense, if perform kidney care on 111 patients (45.7\%), having higher self-reliance, if perform kidney care on 107 people (44\%).

According to regression test in between HBM, knowledge (\%67.6), perceived severity (\%38), self-efficacy (\%31.8) and internal cues to action (16.4\%) have the greatest prediction power and total of construct predict level of $49 \%$ for health behavior of kidneys (Table 4 ). 
Table 4

Predictive power of health belief model constructs in the field of kidney care in type 2 diabetic patients based on logistic regression analysis

\begin{tabular}{|c|c|c|c|c|c|c|}
\hline Variable & Predictive variables & $\begin{array}{l}\text { Non-standard } \\
\text { coefficient B }\end{array}$ & SE & $\begin{array}{l}\text { Standard } \\
\text { coefficient } \\
\text { Beta }\end{array}$ & $\mathrm{p}$ & $\begin{array}{l}\text { Determination } \\
\text { coefficient } \\
\text { R }\end{array}$ \\
\hline \multirow{4}{*}{$\begin{array}{l}\text { Performance of } \\
\text { patients with diabetes } \\
\text { in kidney health related } \\
\text { behaviors }\end{array}$} & -Knowledge & 0.676 & 0.330 & 0.127 & 0.042 & \multirow[t]{4}{*}{0.493} \\
\hline & -Perceived severity & 0.380 & 0.106 & 0.224 & 0.001 & \\
\hline & -Perceived Self-Efficacy & 0.318 & 0.083 & 0.284 & 0.001 & \\
\hline & -Internal cues to action & 0.164 & 0.089 & 0.136 & 0.066 & \\
\hline
\end{tabular}

\section{Discussion}

In this study, HBM construct predict about $49 \%$ variance for health behaviors of kidney in type 2 diabetic patients. In this study, level of knowledge in patients was 69.7 of 100 that show patients' needs to more awareness about diabetic kidney complication. In a study performed on 400 patients that with type 2 diabetic and prevalence in disease complication were high that show of weak awareness in patients. [11].

In other study that performed on 748 people, samples state cues of kidney disease just sides pain and painful urinate and just $12.7 \%$ people aware that diabet is dangerous factor for kidney patients [12] and in other study on Africa people that live America, just $13.6 \%$ and Australia $8.6 \%$ aware to influence of diabetes on kidneys [13-14].

In this study perceived severity and susceptibility in patients achieved in range 82 and 89 score of 100 that show patients are sensitive relative to self-health and themselves find under cause to diabetes kidney complications.

Dogba et al. performed study on diabet patients in Canada and pay attention kidney complication in diabetes, all patients understand that they are important and dangerous complication for this disease [15] that show high perceived severity in patients.

In a study performed in Iran, researcher state that high blood pressure and diabet are basic causes for kidney chronic failure in view of patients [16]. In other study referred to this subject that doctors should be present to improve kidney complication and recognize soon diabetes kidney disease in patients [17].

In this study, patients have aware with achieved benefits for perform health behavior of kidney. Different studies showed that patient have aware of profits in hygienic behavior have better blood sugar control and experience little complication in diabetes [18-19].

Perceived barriers are the most powerful predictors for health behavior in care of kidney, especially, facilitate for accessing patients to supervisions and clinic examination by physician and also to inform patients about an influence diabetes on kidneys can decrease perceived barriers in view of patients and they move to perform kidney care.

In a study, just 21.2\% people know that absence of diabetes cause kidney failure [12] and this factor can led to weakness in relationship patients with doctor and un false assistances, this work create obstacle for perform healthy behavior in kidneys. In other study, just $34.6 \%$ of samples refer to doctors explain kidney complication in self-examination [12].

Self-efficiency determines as behavior predictor with number average (76.9). It seems that with delivering suitable educational program based on HBM, we can close to arise hygienic behavior in patients in this field.

In the United States, the National Kidney Foundation has organized the Kidney Early Evaluation Program (KEEP) that targets the patients with diabetes for educational programs and early kidney disease screening [20,21]. The participants in KEEP are provided with the appropriate information regarding the association of diabetes and CKD. The KEEP also encourages the participants to follow up with their clinicians for prevention and treatment of risk conditions. Participants are followed up by telephone and mail. Follow-up studies have demonstrated that this program has been successful in early identification of individuals with kidney disease, broadening the reach of pre-end stage renal disease (ESRD) education efforts, and reducing ESRD mortality [21]. 
In Iran, in spite of the high incidence of kidney disease and its large economic burden [22], there has been no systematic attempt to improve the awareness of this disease, its risk factors, and consequences in the at-risk individuals. It should be noted that low-cost strategies are most likely to be achievable in Iran due to the limited healthcare resources. A kidney disease awareness program like KEEP can be a useful model in Iran for reducing the incidence of kidney disease among at-risk individuals (i.e. patients with diabetes.

In a study performed on 110 patients that caused to type 2 diabetes patient have weak self-efficiency and this subject increase disease complication and clinic costs [23].

Internal and external cues to action in patients as one internal promotional source and simulation of around environment and patients associates move to hygienic behaviors. In this study, $44 \%$ people pay to kidney supervision pay attention to device to doctors and hygienic personnel [12].

In this study, average of health behaviors of kidneys in diabet patients show that number of patients haven't suitable operation in field of care of kidneys. Pay attention to diabetes disease complication on kidneys and performing hygienic behaviors in this field, education for care of kidneys as regular examinations by health center doctor, blood pressure control, blood sugar control and drink enough water are important. In other studies, related to supervision aspects for diabet, different performance in patients reported [11, 23]. In a study, majority people stated that they refer to doctor every 2 years [12]. In this study by Sankar et al. in Ohayo in America showed relationship between supervision behavior in diabetes and kidney complication in patients, so blood sugar in patients have more relationship with end stage renal disease (ESRD) [24]. In another study refer to role of control behavior and supervision of kidneys and decrease hemodialysis in kidney patients $[25,26]$. In study Ethiopia, there are relationship in unsuitable sugar, when cause kidney diseases in diabetes patients [6].

There are limitations this study that are consist of lack of showing in patients behaviors and collected information by self-reporting. Therefore, these limitations eliminate in studies, when we state of study purposes in first design and patient optionally present for treatment and there are enough time, until they complete questionnaire.

\section{Conclusion}

In type 2 patients with diabetes based on HBM with awareness of diabetes kidney complication, perceived severity, self-efficiency and internal cues to action are part of health behavior predictor care of kidneys. Therefore increasing patients information in field of recognizing kidney complication on role of cues to action and finally increasing self-efficacy in patient infield of care of kidney, should be place in education programs for diabetes patients.

\section{Abbreviations}

HBM: Health Belief Model

T2DM: Type 2 Diabetes Mellitus

FBS: Fasting Blood Sugar

CVI: Content Validity Index

CVR: Content Validity Ratio

\section{Declarations}

\section{Ethics approval and consent to participate}

This study was conducted in accordance with the declaration of Helsinki. This study was conducted with approval from the Ethics Committee of Arak university of medical sciences (Approval ID: IR.ARAKMU.REC.1399.045). Written informed consent was obtained from all participants, and data are being kept confidential and anonymous.

\section{Consent for publication}


Not applicable

\section{Availability of data and materials}

The datasets generated during and analyzed during the current study are available from the corresponding author.

\section{Competing interests}

The authors declare that they have no competing interests.

\section{Funding}

The present article is taken from the Master's thesis approved by Arak University of Medical Sciences (Grant Number: 6141). The funder provided all costs of the thesis and does not have any other roles in conducting and reporting the study results.

\section{Authors' contributions}

The authors' responsibilities were as follows: Study design: MF, MS and MKh; data collection, drafting of the manuscript: AA; analysis and interpretation of the data: MF, MS, MKh and AA; critical revision of the manuscript: MS; study supervision. All authors read and approved the final manuscript.

\section{Acknowledgements}

We would like to thank all of the patients who participated in this study.

\section{References}

1. Guariguata L, Whiting DR, Hambleton I, Beagley J, Linnenkamp U, Shaw JE. Global estimates of diabetes prevalence for 2013 and predictions for 2035. Diabetes research and clinical practice. 2014;103(2):137-49.

2. Etemad K, Heidari A, Panahi M, Lotfi M, Fallah F, Sadeghi S. A Challenges in Implementing Package of Essential Noncommunicable Diseases Interventions in Iran's Healthcare System. Journal of health research in community. 2016;2(3):32-43.

3. Ayalneh ST, Mesfun MG, Abebe G, Getachew H. Renal function assessment among diabetic patients in asella referral and teaching hospital, assela, south east Ethiopia, Science,2019; 8(2): 17-20.

4. Mousavi SSB, Soleimani A, Mousavi MB. Epidemiology of end-stage renal disease in Iran: a review article. Saudi Journal of Kidney Diseases and Transplantation. 2014;25(3):697.

5. Collins A, Kasiske B, Herzog C, Chavers B. US Renal Data System: USRDS 2005 annual data report: atlas of end-stage renal disease in the United States. American Journal of Kidney Diseases. 2006;47:A4.

6. Shiferaw WS, Akalu TY, Aynalem YA. Chronic Kidney Disease among Diabetes Patients in Ethiopia: A Systematic Review and Meta-Analysis. International Journal of Nephrology. 2020. https://doi.org/10.1155/2020/8890331

7. Azar MR, Farahnak Z. Frequency og nephrophaty and its relation to metabolic control in patiented with diabetes melituse. ARYA Atherosclerosis. 2010;3(4).

8. Remuzzi G, Schieppati A, Ruggenenti P. Nephropathy in patients with type 2 diabetes. New England Journal of Medicine. 2002;346(15):1145-51.

9. Mousavi SSB, Hayati F, Ansari MJA, Valavi E, Cheraghian B, Shahbazian H, et al. Survival at 1, 3, and 5 years in diabetic and nondiabetic patients on hemodialysis. Iranian journal of kidney diseases. 2010;4(1):74-7.

10. Shabibi P, mansourian M, abedzadeh M S, sayehmiri K. The Status of Self-Care Behaviors in Patients with Type 2 Diabetes in the City of Ilam in 2014. sjimu. 2016; 24 (2):63-71

URL: http://sjimu.medilam.ac.ir/article-1-3085-fa.html

11. Heshmati H, behnampour N, khorasani F, moghadam Z. Prevalence of chronic complications of diabete and its related factors in referred type 2 diabetes patients in Freydonkenar diabetes center. J Neyshabur Univ Med Sci. $2014 ; 1$ (1):36-43 URL: http://journal.nums.ac.ir/article-1-29-fa.html

12. Roomizadeh P, Taheri D, Abedini A, Mortazavi M, Larry M, Mehdikhani B, et al. Limited knowledge of chronic kidney disease and its main risk factors among Iranian community: an appeal for promoting national public health education programs. Int $J$ Health 
Policy Manag 2014; 2: 161-166. doi: 10.15171/ijhpm.2014.37

13. Waterman AD, Browne T, Waterman BM, Gladstone EH, Hostetter T. Attitudes and behaviors of African Americans regarding early detection of kidney disease. Am J Kidney Dis 2008; 51: 554-62. doi: 10.1053/j.ajkd.2007.12.020

14. White SL, Polkinghorne KR, Cass A, Shaw J, Atkins RC, Chadban SJ. Limited knowledge of kidney disease in a survey of AusDiab study participants. Med J Aust 2008; 188: 204-8.

15. Dogba MJ, Dipankui MT, Chipenda Dansokho S, Légaré F, Witteman HO. Diabetes-related complications: Which research topics matter to diverse patients and caregivers? Health Expectations. 2018;21(2):549-59.

16. Khazaei Z, Rajabfardi Z, Hatami H, Khodakarim S, Khazaei S, Zobdeh Z. Factors associated with end stage renal disease among hemodialysis patients in Tuyserkan City in 2013. psj. 2014; 13 (1) :33-41

URL: http://psj.umsha.ac.ir/article-1-139-fa.html

17. Nezakati E, Sohrabi M B, Zolfaghari P, Amerian M, Madani S, Yahyaei M et al . The prevalence and related factors of diabetic nephropathy in Shahroud. MEDICAL SCIENCES. 2015; 25 (1) :65-70 URL: http://tmuj.iautmu.ac.ir/article-1-908-fa.html

18. Chow WL, Joshi VD, Tin AS, van der Erf S, Lim JF, Swah TS, et al. Limited knowledge of chronic kidney disease among primary care patients-a cross-sectional survey. BMC Nephrol 2012; 13: 54. doi: 10.1186/1471-2369-13-54

19. Hemmelgarn BR, Zhang J, Manns BJ, James MT, Quinn RR, Ravani P, et al. Nephrology visits and health care resource use before and after reporting estimated glomerular filtration rate. JAMA 2010; 303: 1151-8. doi: 10.1001/jama.2010.303

20. Vassalotti JA, Li S, Chen SC, Collins AJ. Screening populations at increased risk of CKD: the Kidney Early Evaluation Program (KEEP) and the public health problem. Am J Kidney Dis 2009; 53: S107-14. doi: 10.1053/j.ajkd.2008.07.049

21. Whaley-Connell AT, Vassalotti JA, Collins AJ, Chen SC, McCullough PA. National Kidney Foundation's Kidney Early Evaluation Program (KEEP) annual data report 2011: executive summary. Am J Kidney Dis 2012; 59: S1-4. doi: 10.1053/j. ajkd.2011.11.018

22. Tohidi M, Hasheminia M, Mohebi R, Khalili D, Hosseinpanah F, Yazdani B, et al. Incidence of chronic kidney disease and its risk factors, results of over 10 year follow up in an Iranian cohort. PLoS One 2012; 7: e45304. doi: 10.1371/journal.pone.0045304

23. Firooz M, Hosseini SJ, Mazlom SR, Hasanzadeh F, Kimiyaee SA. Self-care of patient with diabetes type II. Journal of Sabzvar university of medical sciences . 2014; 22(6): 1018-1025.

24. Navaneethan SD, Schold JD, Jolly SE, Arrigain S, Winkelmayer WC, Nally Jr JV. Diabetes control and the risks of ESRD and mortality in patients with CKD. American Journal of Kidney Diseases. 2017;70(2):191-8.

25. Rhee JJ, Ding VY, Rehkopf DH, Arce CM, Winkelmayer WC. Correlates of poor glycemic control among patients with diabetes initiating hemodialysis for end-stage renal disease. BMC nephrology. 2015;16(1):204.

26. Maclsaac R, Ekinci E, Jerums G. Markers of and Risk Factors for the Development and Progression of Diabetic Kidney Disease. Am J Kidney Dis. 2014;63(2)(suppl 2):S39-S62 